\title{
ANALYSIS OF THE STRINGER-TO-CROSS-BEAM RIVETED JOINTS BEHAVIOUR
}

\author{
Josef VIČAN ${ }^{1, *}$, Jozef JOŠT ${ }^{1}$, Jozef GOCÁL ${ }^{1}$ \\ ${ }^{1}$ Department of Structures and Bridges, Faculty of Civil Engineering, University of Žilina, Žilina, Slovak \\ Republic. \\ corresponding author: vican@fstav.utc.sk.
}

\begin{abstract}
The main aim of the paper is to present results of the numerical and experimental studies related to the analysis of the real stiffness of the stringer-to-cross-beam connection in order to avoid approximation of this joint by means of complicated 2D modelling and to use simplified 1D model for global analyses of bridges with open bridge decks.
\end{abstract}

\section{Keywords:}

Bending moments;

Bridges;

Connection;

Finite element model;

Railway;

Riveted joints;

Stringer-to-cross-beam.

\section{Introduction}

Many existing bridges constructed in Slovakia after War World II are made of steel members mutually connected by riveted joints. Due to complicated and not sufficiently known behaviour of joints used for connecting the open bridge deck members in railway bridges, an experimental and theoretical analysis supported by numerical modelling was applied to solve the partial problems related to the real joint behaviour and modification of the current standard approaches valid for the new bridges to be acceptable for the existing ones. The research was focused on the analysis of the stringer-tocross-beam connection stiffness of railway bridges with open bridge decks. The main aim of the performed study was to observe the real stiffness of the abovementioned connections in order to avoid approximation of those joints by means of complicated 2D modelling and to use simplified 1D model for global analyses of those types of bridges. Two variants of one of the typical stringer-tocross-beam connections, analysed in this study are shown in the Fig. 1.

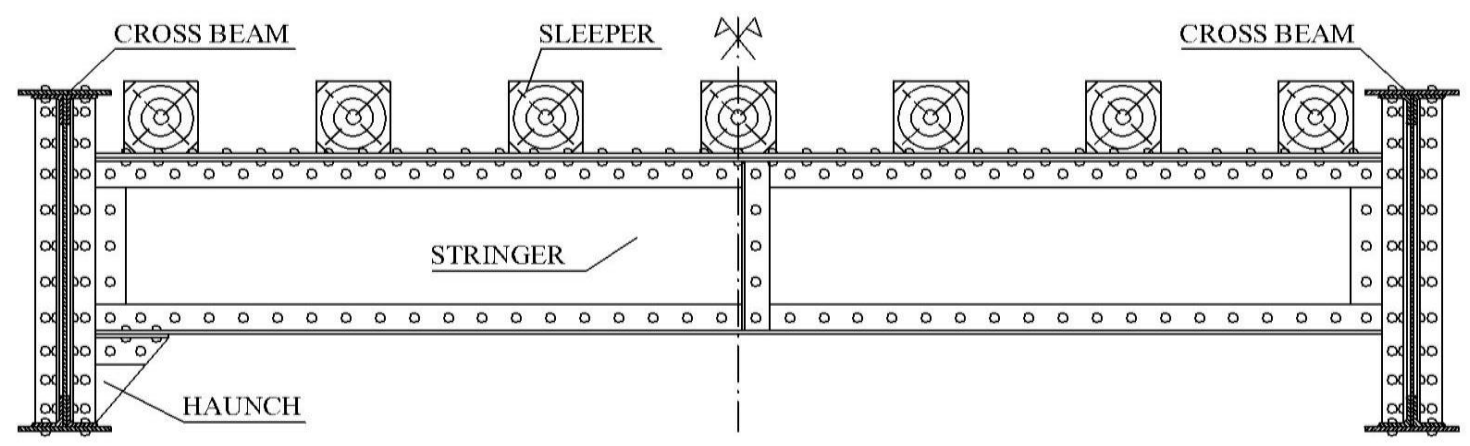

Fig. 1: Configuration of the typical real stringer with/without reinforcing haunches.

\section{Experimental and numerical analysis of the stringer-to-cross-beam connection}

The aim of this experimental and numerical analysis was to determine actual stiffness of the typical stringer-to-cross-beam riveted connection and to find and develop the optimal numerical model representing the real behaviour of the connection.

The joint stiffness significantly influences the distribution of internal forces, especially moments, among members mutually connected in the joint. Therefore, the correct modelling of the joint is very 
important not only from the viewpoint of member resistance verification, but also in conjunction with fatigue assessment of the riveted detail [1].

Firstly, the experimental model of the individual stringer-to-cross-beam riveted connection was investigated by means of specimens, which were tested in the laboratory of Civil Engineering Faculty to determine the stiffness of the detail experimentally. The joint tested in the laboratory introduced the oldest riveted connection, where only webs of both deck elements are mutually connected using connecting angles. In order to investigate the riveted joint only, a special cross-beam was used to simulate the real joint condition (see Fig. 2).
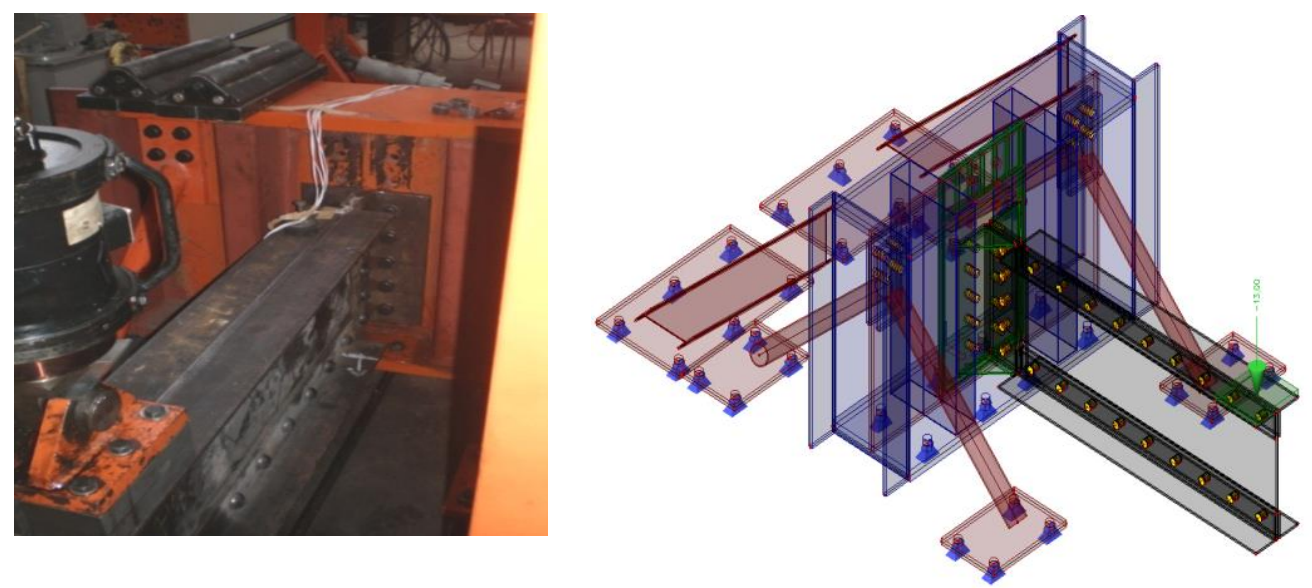

Fig. 2: Laboratory sample of the riveted stringer-to-cross-beam connection and its numerical model.

The common static scheme of real stringer connected with the cross-beam by means of both members webs only is a two hinged beam (supported by cross-beams), loaded by reactions from sleepers (see Fig. 1). However, due to limited possibilities of the laboratory conditions as well as due to the economic aspect, a cantilever loaded at the free end by one force successively growing up to the limit value of $100 \mathrm{kN}$ was applied as the static scheme for laboratory testing. At the point of application of the loading force, the deformation sensor was situated to record the stringer deflections. The measured deflections of the stringer modelled as cantilever are presented in Table 2, compared to the results of numerical calculations.

Secondly, the numerical models were created using software environment Scia Engineer. To develop the real and optimal model respecting the real behaviour of this joint, 5 types of numerical models were created, whose descriptions and figures are presented in Table 1.

Based on the results comparison of the stringer deflections measured within the experimental observation and the numerical ones, as presented in Fig.3, the model of type A provides the closest outputs to the experimentally measured deflections.

On the contrary, it is also evident that the model of type $E$ seems to be not acceptable for modelling the observed type of connection.

Nevertheless, from the viewpoint of practical utilization, the creation and application of the model of type $A$ is rather complicated due to approximations of all joint members by means of shell element including rivets. Only the prestressing in rivets due to thermal treatment and friction caused by the prestressing were neglected in this model. But this type of modelling investigated joints in real existing bridge structures is very time-consuming process, so that this model seems to be less effective than approximation of the real joint by means of model of type $B$ or $C$. The model of type $B$ and $C$ are very close one to each other, because in both cases the rivets are modelled by means of beam elements. In the case of model type of $B$, the combination of shell and beam elements was used to approximate a rivet and to allow for the influence of the rivet hole more precisely. For approximation of connection by means of model $\mathrm{C}$, the partial members of the joint were modelled by the shell elements, only behaviour of rivets were approximated using beam elements. This type of model introduces the most simplified approximation enabling very effective analyse, but the accuracy of the calculated results is lower (see Fig. 4). What type of model should be used for approximation of those joints depends on the type of analysis. For a global analysis of the whole 
bridge structure, the model of type $C$ is sufficient. But for more accuracy calculations of local stress condition around the rivet hole, the more sophisticated model of type A or B is suitable.

The graphical presentation of the stringer deformations calculated using the model of type $A$ is shown in Fig. 3.

Table 1: Figures and description of the models developed to analyze the joint behaviour.

\begin{tabular}{|c|c|c|}
\hline $\begin{array}{l}\text { Figures of } \\
\text { models }\end{array}$ & $\begin{array}{c}\text { Model } \\
\text { Designations }\end{array}$ & Model of the stringer-to-cross-beam connection description \\
\hline$z^{*}$ & Type A & $\begin{array}{c}\text { The web of stringer, cross-beam, and connecting angles } \\
\text { are modelled by means of shell elements. The rivets } \\
\text { are modelled by shell elements too. }\end{array}$ \\
\hline & Type B & $\begin{array}{c}\text { The web of stringer, cross-beam, and connecting angles } \\
\text { are modelled using shell elements. The rivets are modelled } \\
\text { by shell and beam elements. }\end{array}$ \\
\hline & Type C & $\begin{array}{c}\text { The web of stringer, cross-beam, and connecting angles } \\
\text { are modelled by means of shell elements. The rivets } \\
\text { are modelled by beam elements. }\end{array}$ \\
\hline & Type D & $\begin{array}{l}\text { The web of stringer, cross-beam, and connecting angles } \\
\text { are modelled using shell elements. The connection of connecting } \\
\text { angles to the web of cross-beam is modelled by beam elements. } \\
\text { The connections of the connecting angles and the flange angles } \\
\text { to the web of stringer are modelled as fully rigid. }\end{array}$ \\
\hline & Type E & $\begin{array}{l}\text { The web of stringer, cross-beam, and connecting angles } \\
\text { are modelled using shell elements. The connections } \\
\text { of the connecting angles to the web of cross beam, as well as } \\
\text { the connections of the connecting angles and the flange angles } \\
\text { to the web of stringer, are modelled as fully rigid. }\end{array}$ \\
\hline
\end{tabular}

Table 2: Comparison of stringer deflections.

\begin{tabular}{|c|c|c|c|c|c|c|}
\hline \multicolumn{3}{|c|}{ Experimentally and numerically obtained deflections of the stringer } \\
\hline \multirow{2}{*}{$\begin{array}{c}\text { Loading } \\
{[\mathbf{k N ]}]}\end{array}$} & $\begin{array}{c}\text { Experimental values } \\
\text { [mm] }\end{array}$ & \multicolumn{5}{|c|}{ Numerical values [mm] } \\
\cline { 2 - 7 } & & $\mathbf{A}$ & $\mathbf{B}$ & $\mathbf{C}$ & $\mathbf{D}$ & $\mathbf{E}$ \\
\hline 6.00 & -1.96 & -1.20 & -1.30 & -1.80 & -1.50 & -0.70 \\
\hline 9.00 & -2.27 & -1.90 & -2.00 & -2.70 & -2.30 & -1.00 \\
\hline 12.00 & -2.61 & -2.50 & -2.70 & -3.50 & -3.00 & -1.40 \\
\hline 15.00 & -2.94 & -3.10 & -3.30 & -4.40 & -3.80 & -1.70 \\
\hline 18.00 & -3.30 & -3.70 & -4.00 & -5.30 & -4.50 & -2.10 \\
\hline 20.00 & -3.56 & -4.10 & -4.50 & -5.90 & -5.00 & -2.30 \\
\hline 22.00 & -3.76 & -4.60 & -4.90 & -6.50 & -5.50 & -2.50 \\
\hline 50.00 & -9.42 & -10.40 & -11.10 & -14.80 & -12.60 & -5.80 \\
\hline 100.00 & -24.40 & -20.70 & -22.30 & -29.60 & -25.10 & -11.60 \\
\hline
\end{tabular}




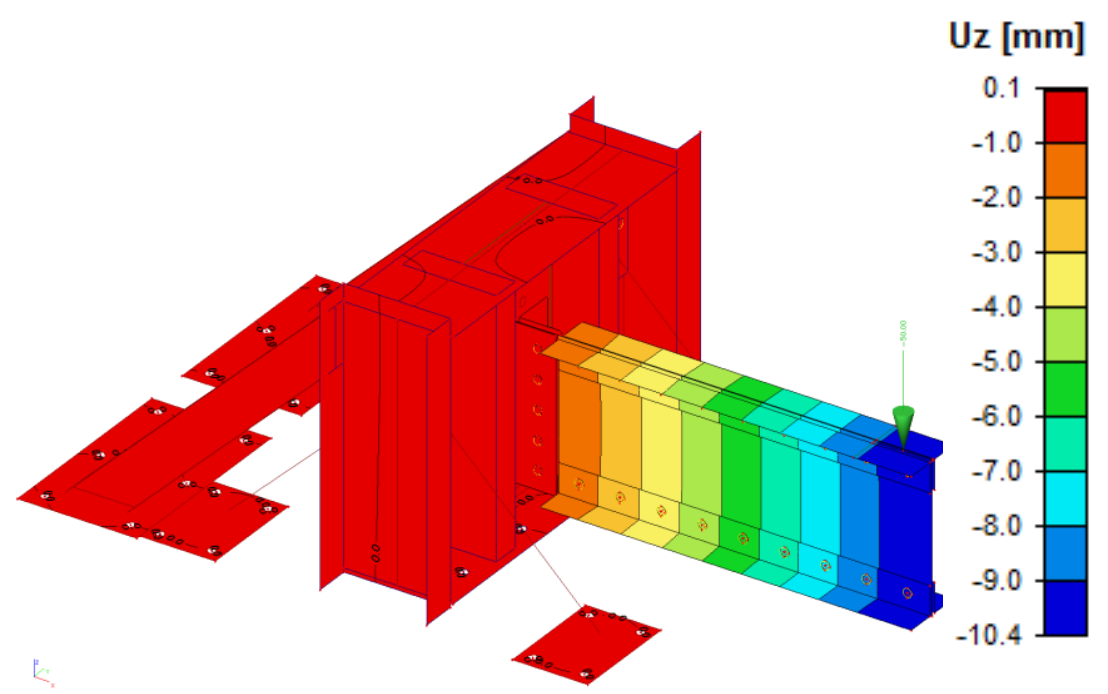

Fig. 3: Graphical outputs of deformations of shell model of type A calculated by means of SCIA Engineer.

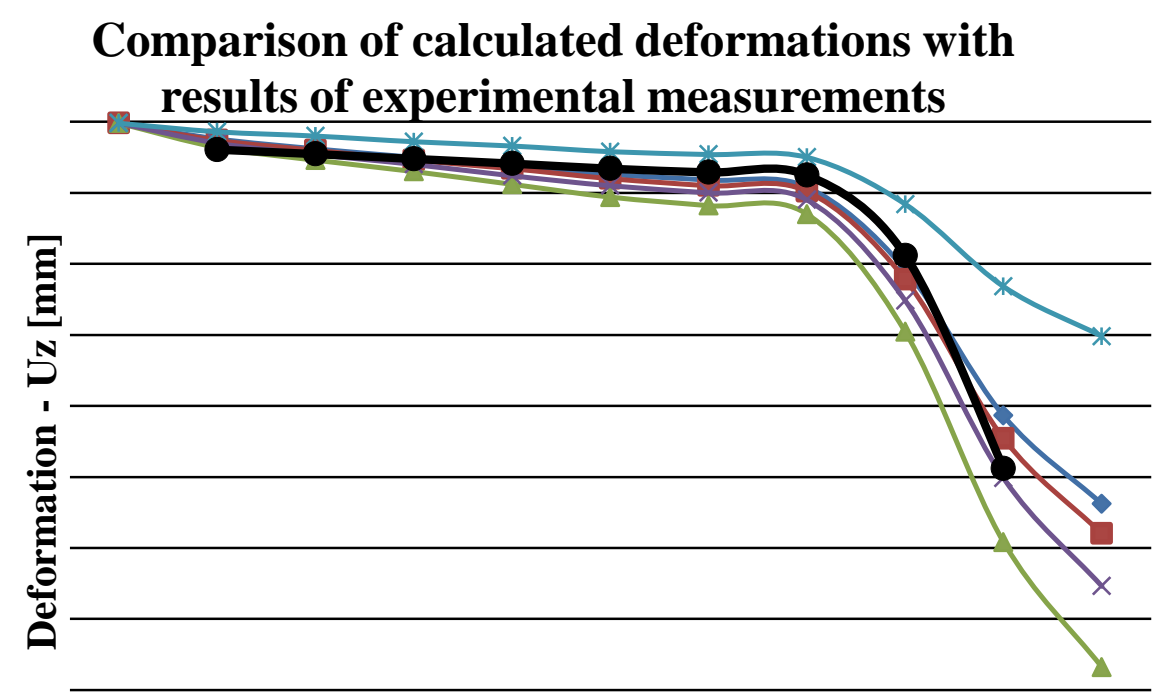

\section{Loading [N]}

$\rightarrow$ Deformations calculed using FEM model of type A

- -Deformations calculed using FEM model of type $B$

$\rightarrow$ Deformations calculed using FEM model of type $C$

* Deformations calculed using FEM model of type $D$

*-Deformations calculed using FEM model of type $\mathbf{E}$

-Laboratory measurement of the beam

Fig. 4: Comparison of calculated deformations with results of experimental measurements.

\section{Numerical analysis of the stringer-to-cross-beam connection stiffness}

To analyse the behaviour of the stringer-to-cross-beam connection, the numerical parametric study was done. Three type of typical stringer-to-cross-beam connections were taken into account, which represent the main types of all those joints. 
Type 1 represents the oldest case of the stringer-to-cross-beam connection, in which both elements, i.e. stringer and cross-beam, are connected by their webs only using connecting angles to construct the joint. This type of stringer-to-cross-beam connection was also tested experimentally (see chapter 2). Type 2 introduces a detail coming from the 70s of the last century trying to develop continuous static system, but with statically vague connection detail of the bottom stringer flange in the direction of z-axis especially. Type 3 represents the newest type of this structural detail with sufficient stiffness due to interconnection of both stringer flanges through the cross-beam, representing possibility to consider the joint as rigid in both main axis $y$ and $z$ too [2]. Numerical analysis of the stringer-to-cross-beam connection stiffness was accomplished using the complex shell model of the complete plate girder bridge with open bridge deck approximated by shell elements also. The effect of local load acting on the deck members was only considered, so that the main plate girders were supported at the locations of cross-beams connections. A parametric study was performed, in which three types of stringer-to-cross-beam connections mentioned above were considered in dependence on the stringer span of 3.0 or $2.0 \mathrm{~m}$, respectively. Numerical models of the individual types of connections are presented in Fig. 5.

Type 1

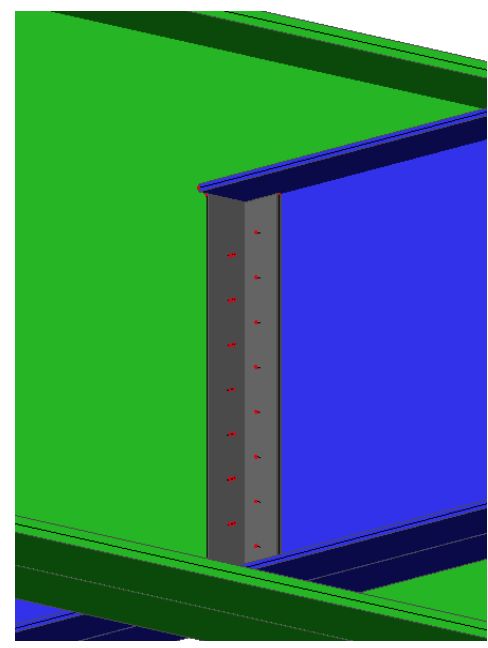

Type 2

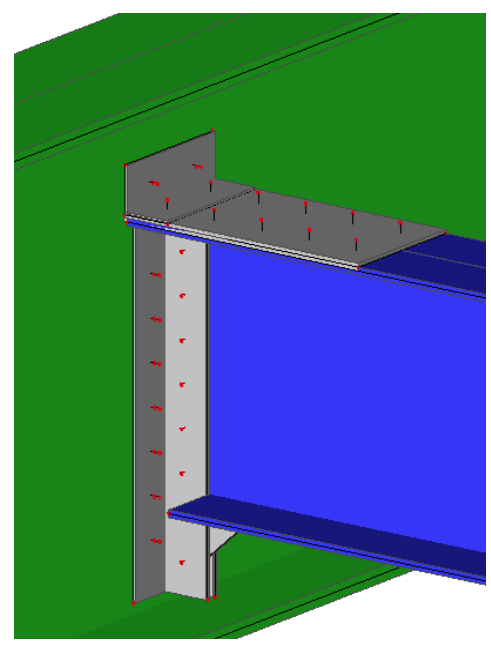

Type 3

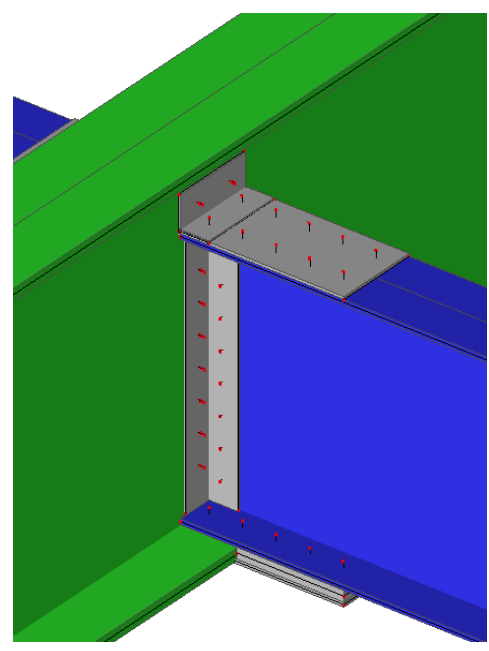

Fig. 5: Detailed types of investigated connections approximated by the FEM models.

In the parametric study, the model of type $C$ described in chapter 2 was applied, in which the shell elements were used to approximate all the structural members of the railway bridge. Rivets in the stringer-to-cross-beam connections were only modelled by means of beam elements.

Results of the numerical calculations are presented in Fig. 7 and 8, compared to results obtained using elementary bridge computational model, in which all bridge members are approximated by means of beam elements only, and the stringer-to-cross-beam connections are modelled as hinged joint or the rigid one, respectively (see Fig. 6).
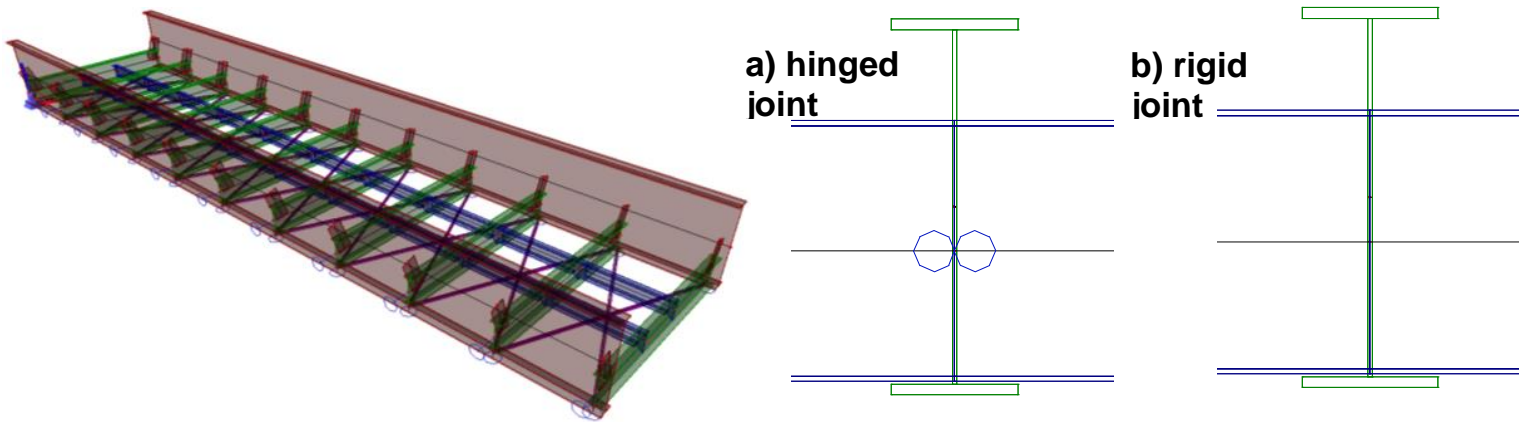

Fig. 6: Beam finite element model with detail of connection stringer to cross-beam, a) hinged joint, b) rigid joint. 
Type 1 - Bending Moments Diagram-Span 3.0m

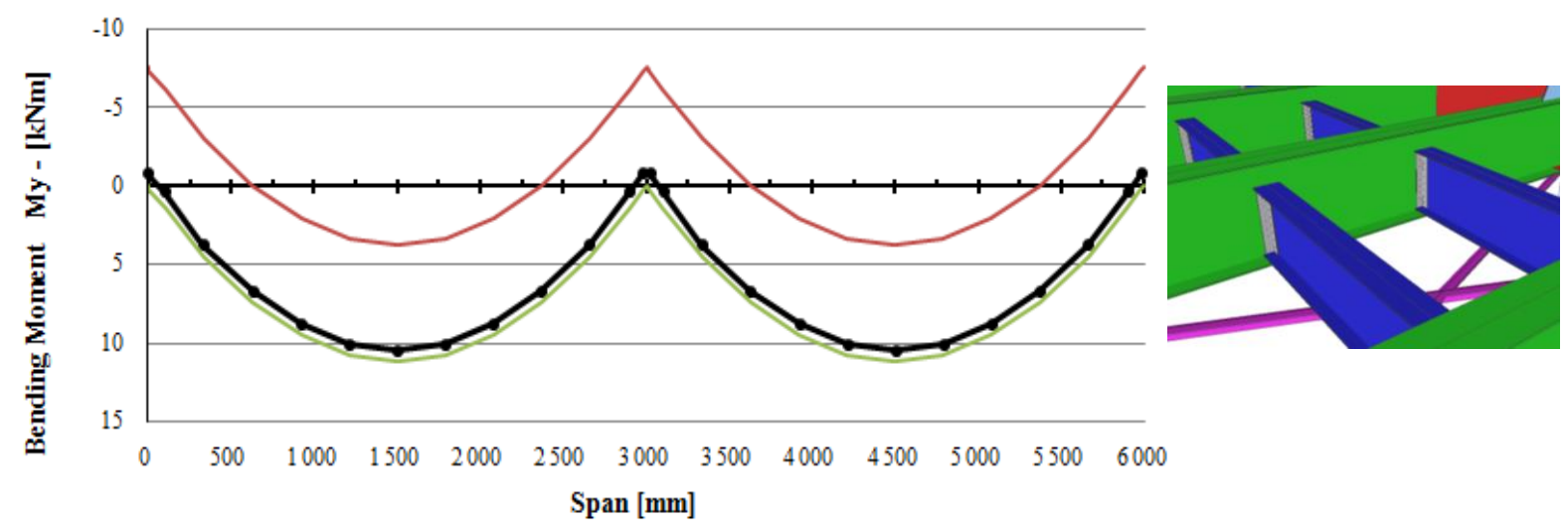

-Shell Model —Beam model - rigid joint —Beam model - pined joint

Type 2 - Bending Moments Diagram-Span 3.0m

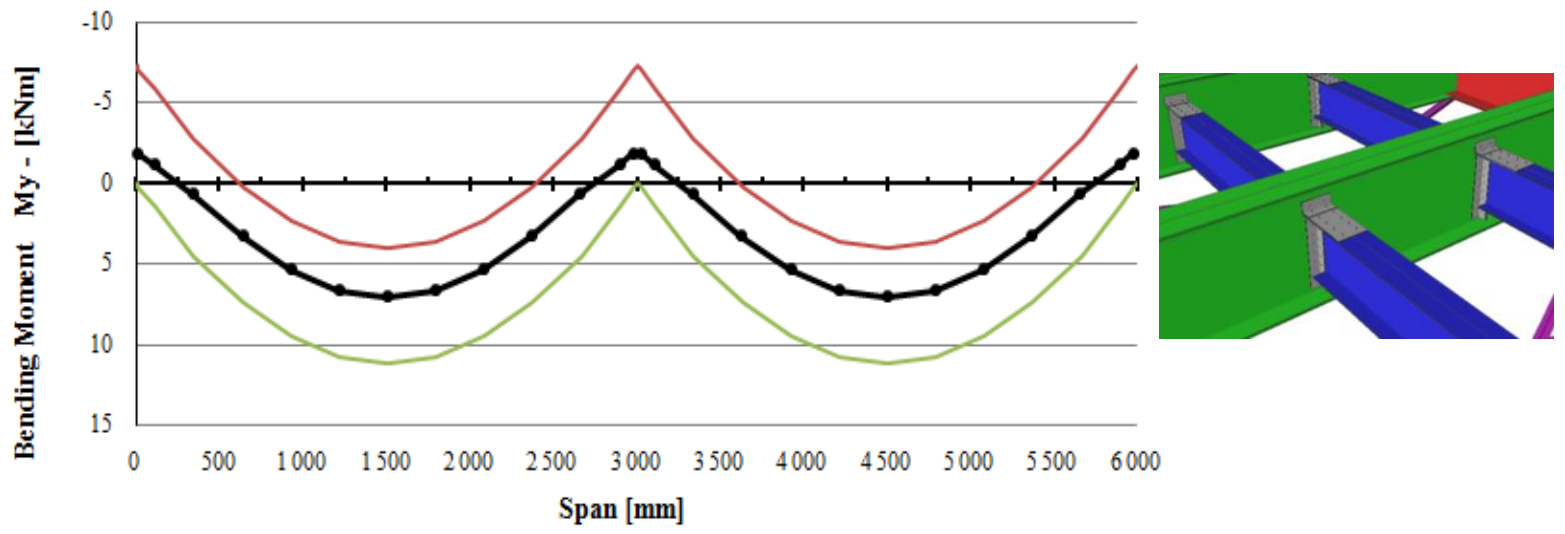

$\rightarrow$ Shell Model $\quad$ - Beam model - rigid joint $\quad$ Beam model - pined joint

Type 3 - Bending Moments Diagram-Span 3.0m

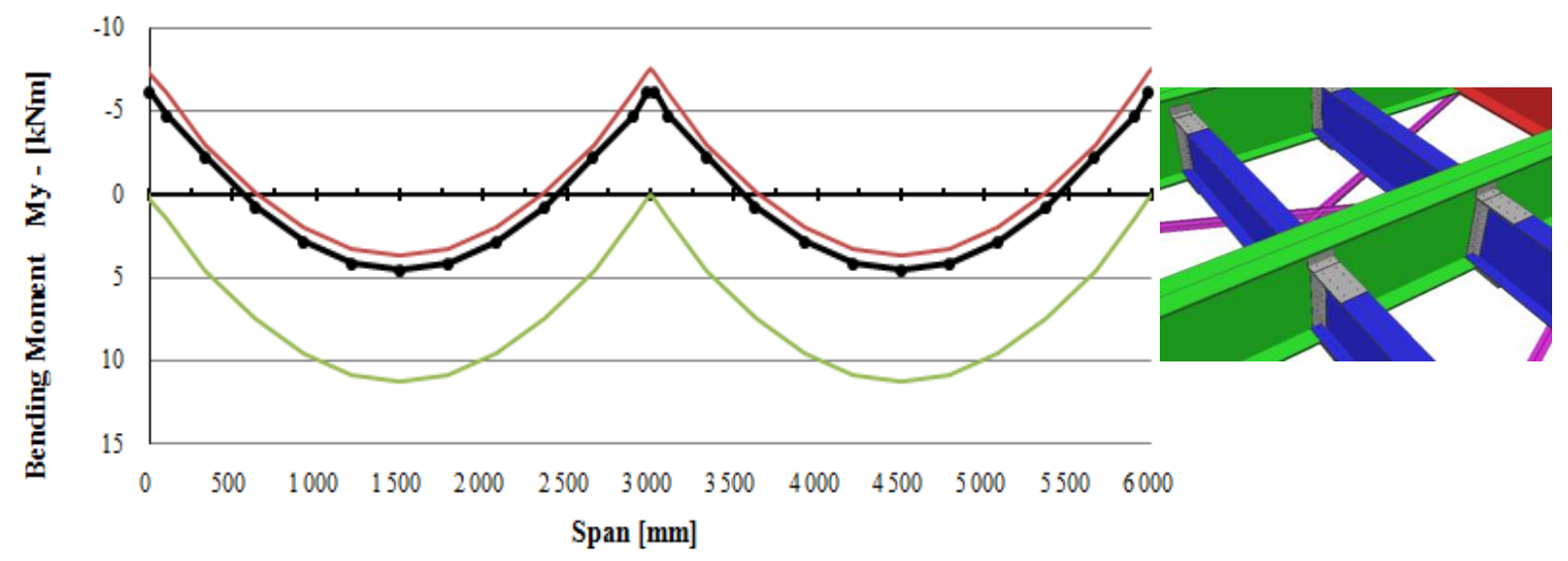

$\rightarrow$ Shell Model —Beam model - rigid joint - Beam model - pined joint

Fig. 7: Graphical comparison of results of parametric study of the observed connection in the case of span of stringer $3.0 \mathrm{~m}$. 
Type 1 - Bending Moments Diagram-Span 2.0m

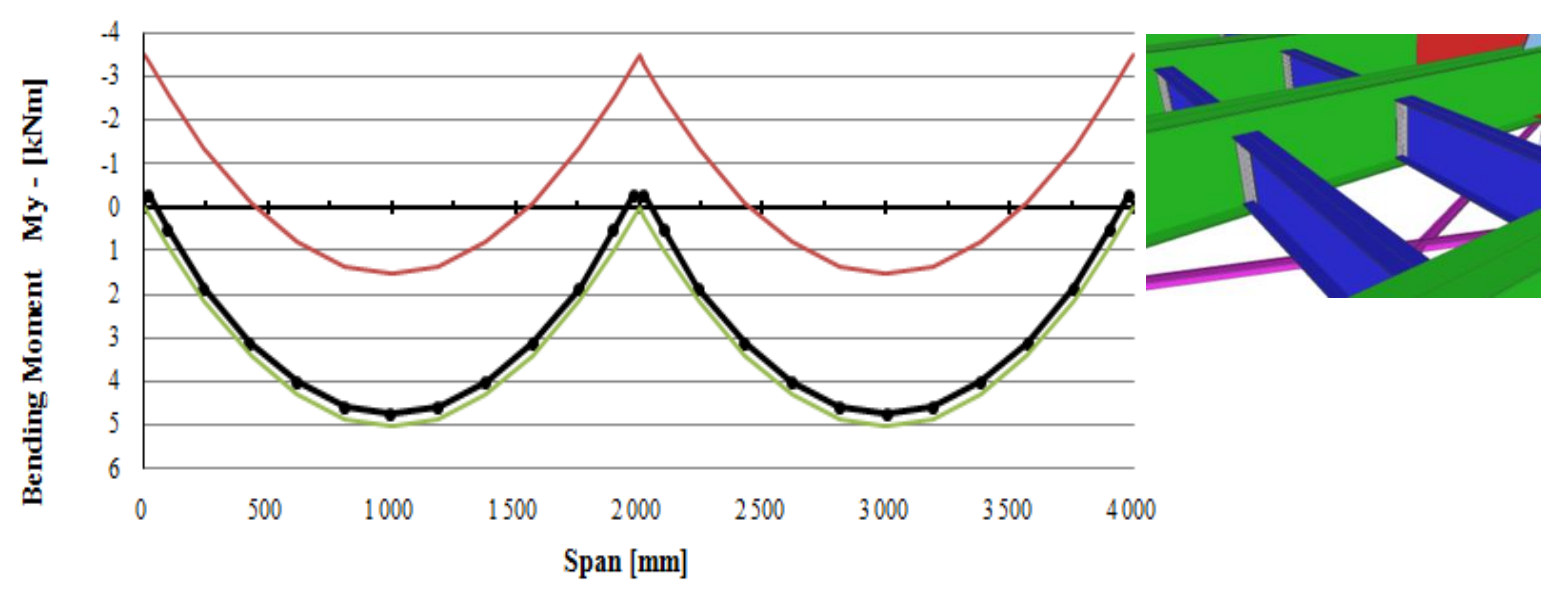

$\rightarrow$ Shell Model $\quad$ Beam model - rigid joint $\quad$ Beam model - pined joint

Type 2 - Bending Moments Diagram-Span 2.0m

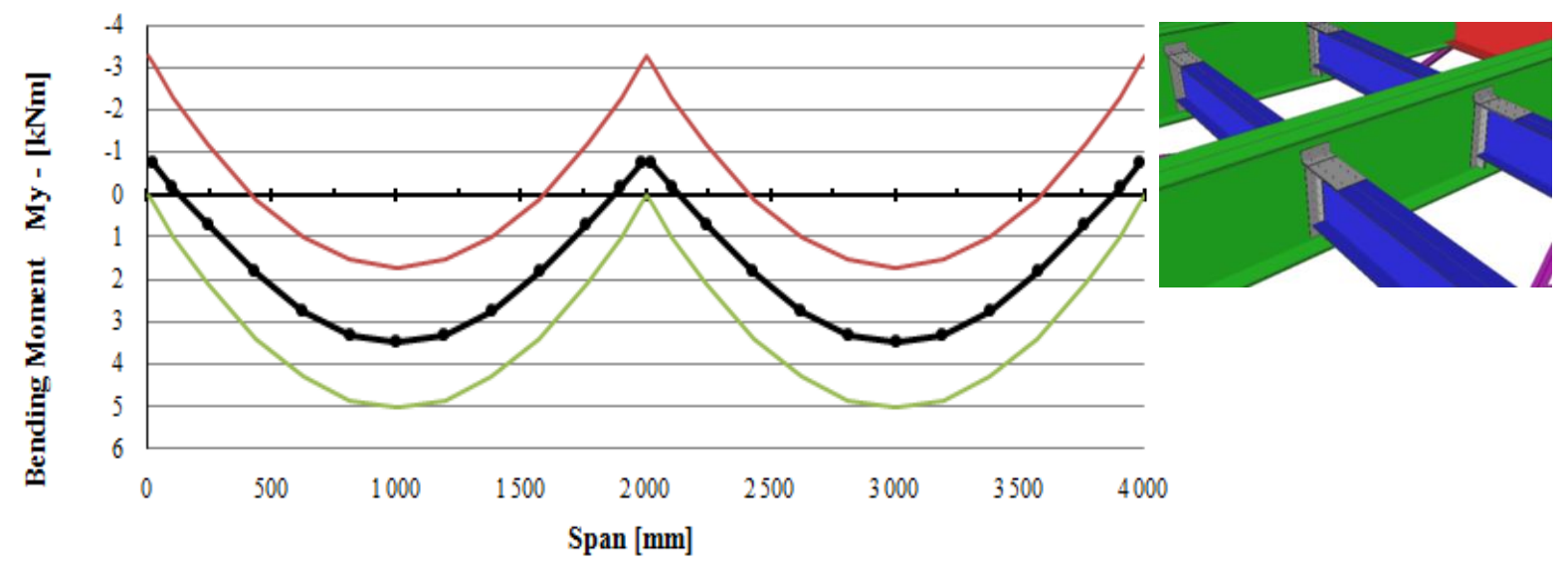

-Shell Model — Beam model - rigid joint _ - Beam model - pined joint

Type 3 - Bending Moments Diagram-Span 2.0m

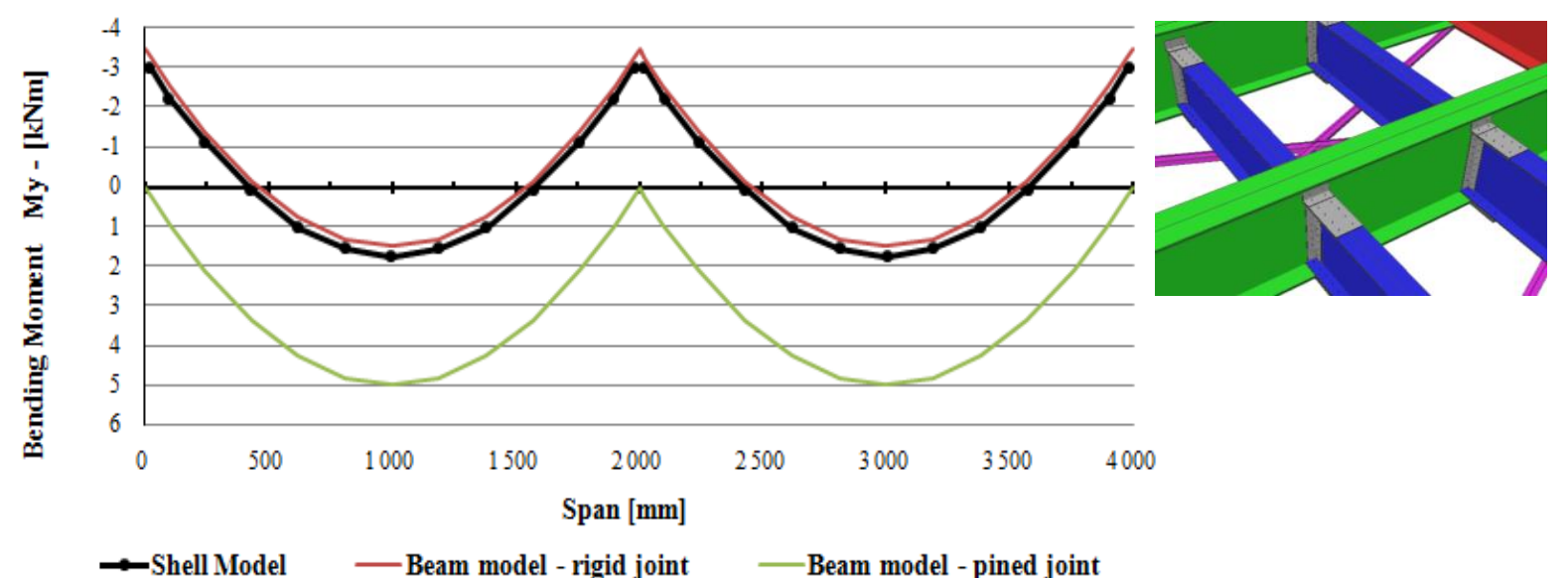

Fig. 8: Graphical comparison of results of parametric study of the observed connection in the case of span of stringer $2.0 \mathrm{~m}$. 


\section{Experimental and numerical analysis of the joint stiffness on the real railway bridge}

Numerical parametric study presented above was supplemented by the in-situ experimental observation of the stringer-to-cross-beam connection stiffness performed on the real railway bridge situated in km 303.309 of the track Žilina - Košice, near the railway station Turany. The basic information related to the bridge geometrical parameters were presented in [3], [4]. The bridge configuration is evident from the Fig. 9 .
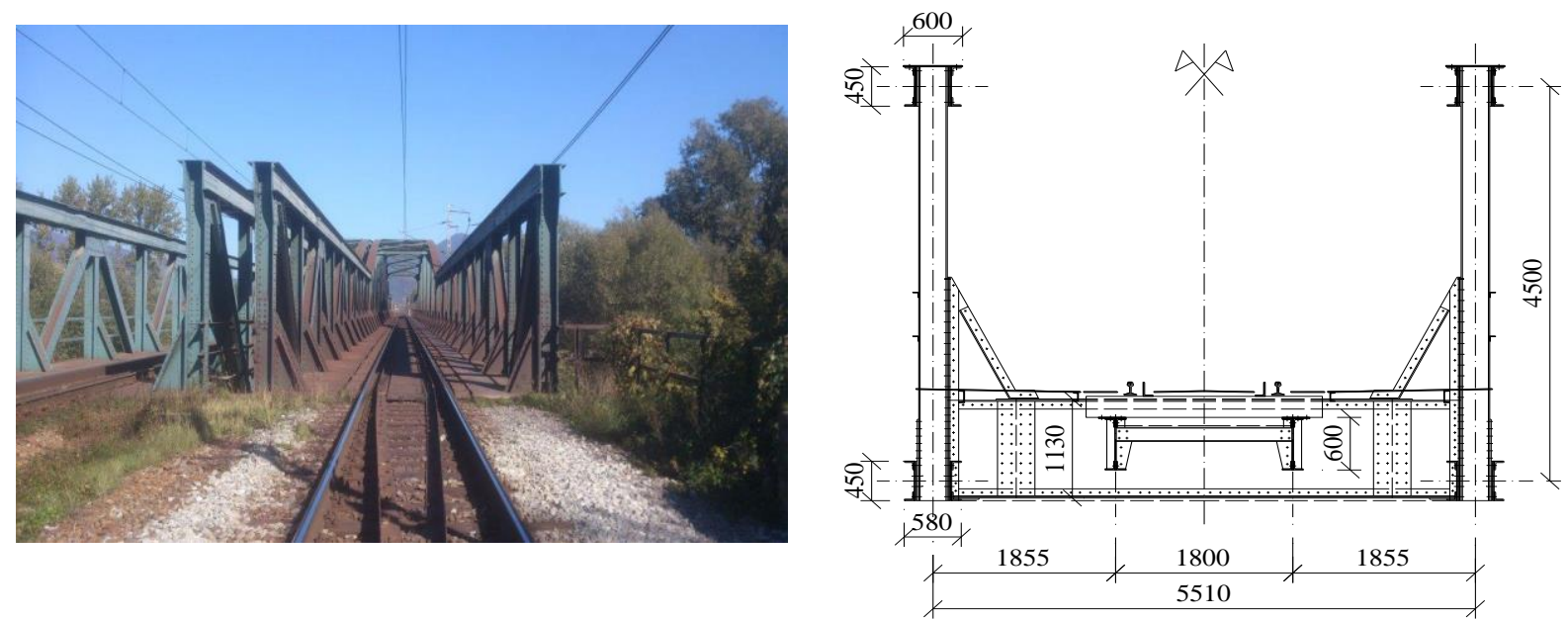

Fig. 9: Railway bridge near the station Turany in km 303,309 of the track Žilina - Košice.
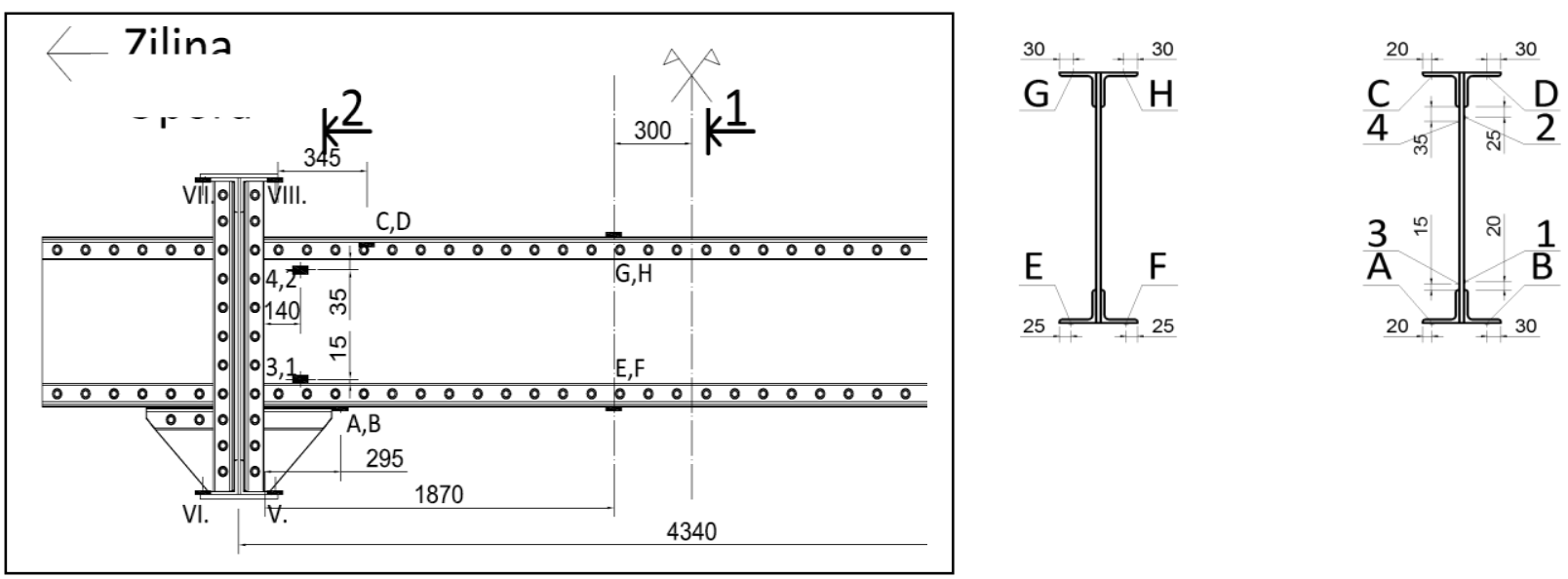

Fig. 10: Stress gauges configuration on the investigated stringer of railway bridge open deck.

Experimental investigation was realised in October 2013. The geometric parameters of the investigated stringer-to-cross-beam joint and the arrangement of gauges are presented in Fig. 10. Within the accomplished measurements, passages of 15 trains were recorded, from which there were 3 freight trains and 12 passenger trains. The recorded courses of stress response to the traffic loads in the individual measured points in the midspan and near the cross-beam, respectively (Fig. 10), were graphically processed using software Microsoft Excel and they are presented in Fig. 12 and 13, respectively.

The experimental investigation of the observed stringer-to-cross-beam connection is supplemented by the numerical analysis using spatial computational model developed in FEM software SCIA Engineer (see Fig. 11), which was created by means of beam elements only. Therefore, the connections of both deck members were approximated by nominally hinged connections or by the rigid ones, respectively (see Fig. 6). The stresses measured during the passage of one passenger train over the bridge are compared with stresses calculated for the same passenger 
train. From the Figures 12 and 13 it can be seen, that the actual behaviour of the observed joint is closer to the rigid connection. The stiffness of the joint is significantly influenced by strengthening haunches connecting the stringer bottom flange with the cross-beam bottom flange. This connection considerably increases the joint stiffness, so that its behaviour seems to be closer to the rigid joint than to the nominally hinged one. However, it is necessary to say that the stresses in the stringer may be more or less affected also by the stiffness of the connection of the cross beam to the main girders, which has been considered as nominally hinged in the numerical analysis (see Fig. 11). In case of considering certain stiffness of this joint it can be expected that the stresses in the stringer would be affected due to higher cooperation of the bridge deck with the main girders. The actual behaviour of the cross-beam-to-main-girder connection will be a subject of the following research.

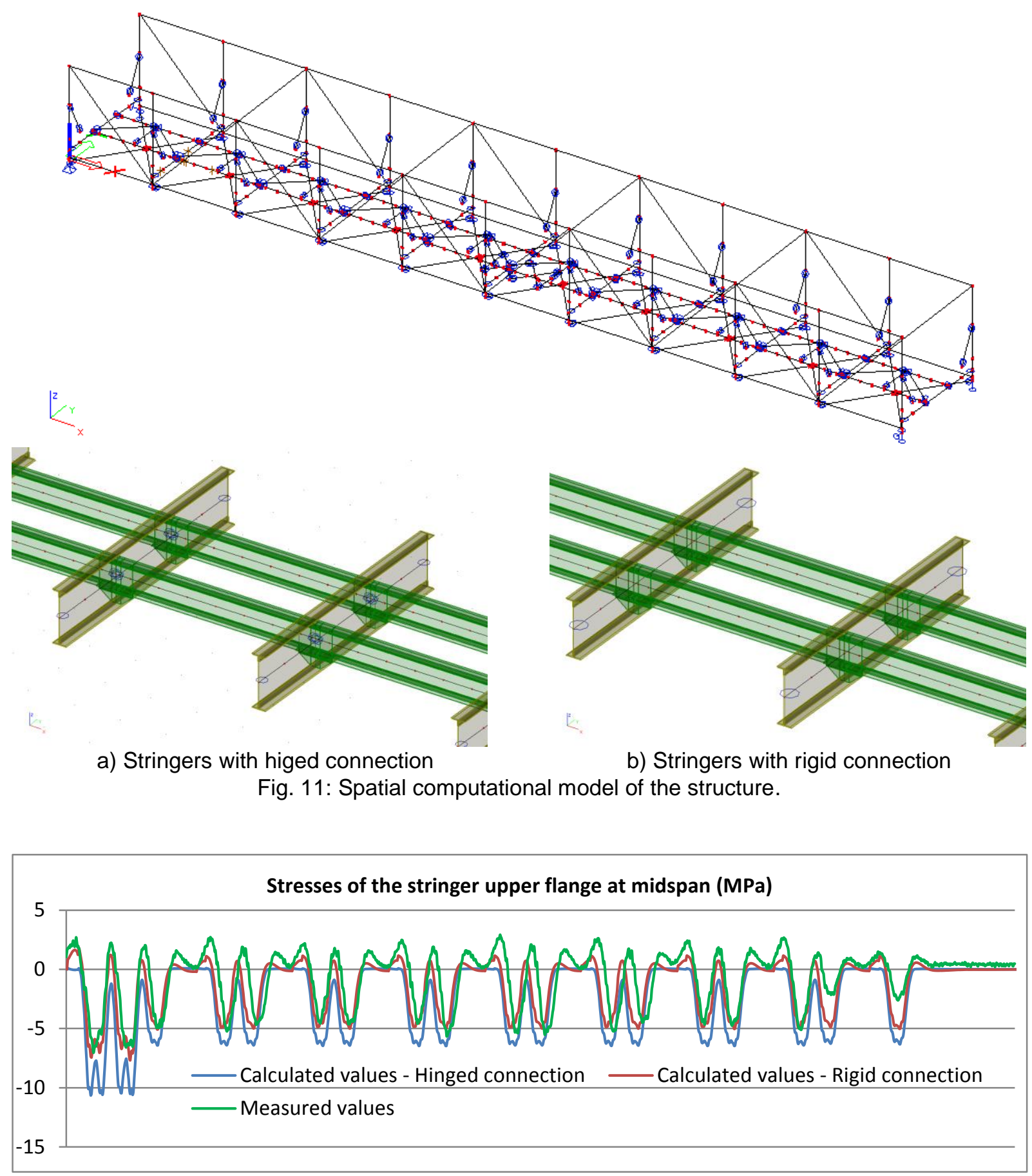




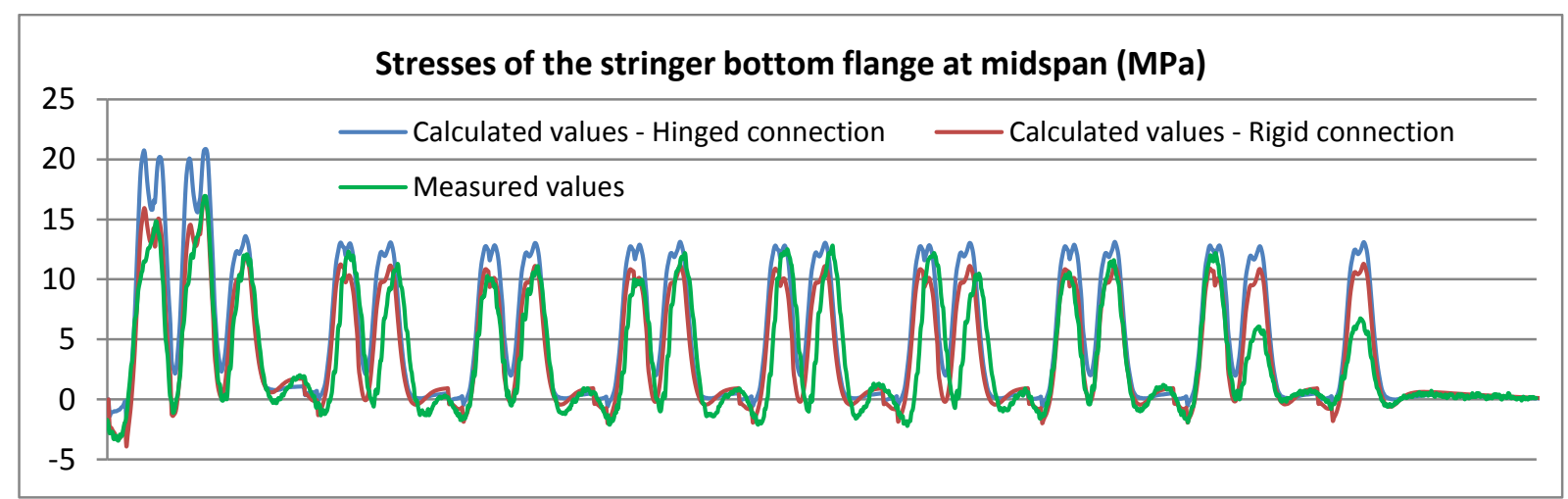

Fig. 12: Stress response in flanges at the midspan of stringer.
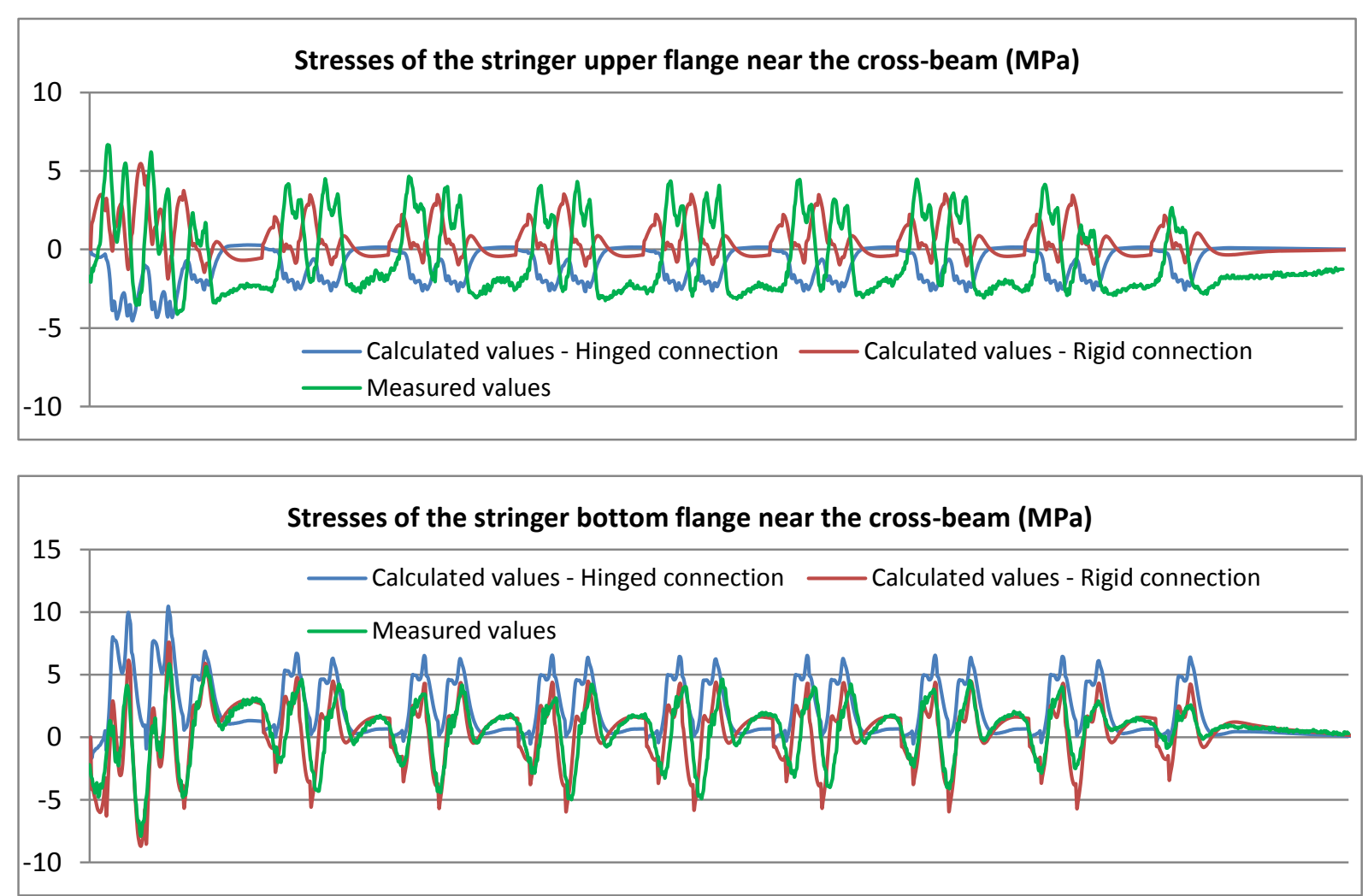

Fig. 13: Stress response in stringer flanges near the cross-beam.

\section{Conclusions}

The paper presents results of the experimental and numerical analyses accomplished in the frame of research activities of our department related to the verification of the actual behaviour of stringer-to-cross-beam joints. Firstly, the optimal numerical model of this joint was found using combined experimental and numerical analyse. Then the parametric study was performed using obtained computational model to analyse usual types of stringer-to-cross-beam connections and to verify actual behaviour of those types of joints. Finally, the results of numerical calculations were compared with the results measured experimentally on the real structural detail of this joint in the existing railway bridge. The results show, that the joint could be modelled as hinged or rigid connection, respectively, using beam elements approximating open bridge deck members. The hinged connections should be used in the case, when stringer-to-cross-beam joint is constructed by connection of webs of both deck members only. In other cases, the behaviour of the joint is closer to the rigid connection. Rigid behaviour of the joint is evident in the case of stringer-to-cross-beam connection constructed according to the type 3, i.e. by interconnection of the both stringer flanges. In the case of joint of type 2 (interconnection of the upper stringer flanges only, with reinforcing 
haunches at the bottom flanges), small corrections should be done to allowing for actual behaviour of the joint. The obtained results proved that some redistribution of the bending moments needs to be taken into account. As a recommendation it could be admitted that $80 \%$ of bending moment of the simply supported (two hinged) stringer should be assumed for the sagging moment in the midspan and $20 \%$ for the hogging moment over the cross-beam.

\section{Acknowledgement}

This work was supported by the Slovak Research and Development Agency under contract APVV-0106-11 and by Research Project No. 1/0364/12 of Slovak Grant Agency. Moreover, the research presented here was supported by the European Regional Development Fund and the Slovak state budget for the project "Research Centre of University of Žilina", ITMS 26220220183.

\section{References}

[1] GOCÁL, J. - VIČAN, J. - HLINKA, R. - JOŠT, J.: Laboratory tests of a typical fatigue prone riveted steel railway bridge structural detail. In Procedia Engineering 2 (2010), pp. 1761-1766.

[2] KVOČÁK, V. - ROTH, O. - HUJDUŠOVÁ, H.: Experimental investigation of end-plated joints. In Steel structures and bridges 2000: 19th Czech and Slovak International Conference: proceedings, Štrbské Pleso, Vysoké Tatry, September 27.-30. 2000. Košice: SvF TU, 2000 S. 187-192. ISBN 80-232-0189-1.

[3] VIČAN, J.- GOCÁL, J.- MELIŠ, B.: Fatigue assessment of existing bridge members. In Communications -Scientific letters of University of Žilina, vol. 9, No. 3, 2007, pp. 11-15, ISSN 1335-4205.

[4] VIČAN, J. - GOCÁL, J. - MELIŠ, B. - KOTEŠ, P. - KOTULA, P.: Real behaviour and Remaining Lifetime of Bridge Structures, In Communications - Scientific Letters of the University of Zilina, vol. 10, No. 2, 2008, pp. 30-37, ISSN 1335-4205. 